\title{
Switching from Traditional to Blended Learning at University Level: Students' and Lecturers' Experiences
}

\author{
W. Marc Jackman \\ Centre for Education Programmes \\ Room 13, Bldg. J Valsayn Campus \\ University of Trinidad \& Tobago
}

\begin{abstract}
This research paper is a reflective account of the implementation of blended learning in terms of the principles and mechanics employed and what it meant for students and lecturers who participated in the course. The process included gathering research evidence, seeking departmental approval, changing the curriculum, experimenting with digital media, specifically; voice overs and video technology; integrating student feedback and interaction and monitoring student learning and accessibility. From the students' perspectives, there was need for greater self-regulation and accountability for covering online material and utilizing online resources in meaningful ways. The research also examined the patterns of access that students utilized (e.g. the days, times and duration with online content, the methods they employed, etc.). The findings revealed that lecturers developed many creative approaches to facilitate online learning using various media. There was also need for much reflective thought and critical thinking in developing the online content especially in terms of integrating post-online dialogue in the face-to-face environment. Overall, this initial foray into blended learning at this university department revealed critical principles and mechanics which were instrumental to the success of the new strategy. The implications of these findings were further explicated.
\end{abstract}

Keywords: education, blended learning and F2F transitions.

\section{Introduction}

The development of digital technologies has created many opportunities for pedagogical change at the university level. Traditional teaching facilitates faceto face interactions with students in lecture and tutorial sessions. Today, digital technology has influenced a paradigm shift in education at university level. Blended learning which combines both traditional and new technologies in curricula delivery is the present and developing trend. In fact, Park, Yu, and Jo 
(2016) identified blended learning as one of the major trends in contemporary higher education. This approach was recently attempted for psychology and other courses at a university in Trinidad.

According to Munir and Prem (2014) extensive research have shown that when blended learning is combined with an adequate amount of face-to-face and online experiences both students and faculty at tertiary level experience greater educational satisfaction. One of the main purposes of blended learning is to enhance engagement through the extension of the learning environment to include one that caters to the inherent needs of millennials and digital natives (Garrison \& Kanuka, 2004; Munir \& Prem, 2014). Luke and Morissey (2014) assert that due to the heavy demands on universities to provide for an ever growing student body blended learning is an innovative approach to teaching through which high quality teaching can still occur. Luke and Morissey also cite Garrison and Kanuka (2004) who see blended learning as an effective strategy that will allow universities to effectively manage the "onslaught of technological developments that will be forthcoming in the next few years" (p. 258-59). Porter and Graham (2016) also advise that examining faculty readiness and perspectives on blended learning must also be taken into consideration for success.

Boelens, Voet and De Wever (2018) also assert that blended learning provides opportunities for greater flexibility in terms of time usage and accommodation a diverse student population outside of the physical walls of the institution.

Boelens, Voet and De Wever (2018) advance that tertiary level institutions could also use blended learning as an attempt to facilitate differentiated instruction as a means of supporting students to achieve.

The research questions for this study include the following:

1. What are the principles and mechanics of implementing a blended instruction?

2. What benefits and challenges do students report from the blended learning experience?

3. What benefits and challenges do lecturers report from the blended learning experience?

\section{Literature Review}

Blended learning is seen as the careful fusion of traditional face-to-face classroom interaction with written online communication (Munir \& Prem, 2014). Blended learning has also been defined as approaches that allow students to engage with learning outside of the classroom with synchronous tools that afford, group chat, Skype communication and web conferencing or asynchronous tools such as discussion forums, blogs or social media networking scenarios (Tshabalala, Ndeya-Ndereya, \& van der Merwe, 2014). Park, Yu, and Jo (2016) also found that communication and collaboration as well as delivery and discussion were critical elements of blended learning implementation. 
According to Ashley (2003), synchronous communication tools allow for immediate communication among individual in an online environment, whereas asynchronous tools enable communication and collaboration over a period of time through a "different time-different place" mode. In the latter, individuals dialogue with each other in their own time and space. Heinze (2008) admits that blending learning is not cleanly defined in the literature but is subject to the nuances and strategies employed in the implementer's context. Notwithstanding the lack of clarity and sometimes confusion with regards to the definition and operationalization of blended learning, it is seen as the pedagogy of the present and the future with the potential to transform tertiary level education in positive ways for both lecturers and students (Garrison \& Kanuka, 2004; Lee, Kim \& Lim, 2017; Tshabalala, Ndeya-Ndereya, \& van der Merwe, 2014). Some researchers argue that courses can only be defined as blended learning if students have control and determination over the place, time, pace or path of the online learning activities (Luke \& Morrissey, 2014; Garrison \& Kanuka, 2004).

According to Arani (2015), among the benefits of blended learning that students advanced are (a) the opportunity that it allows for self-pacing during the learning process (b) the convenience of accessing course content and material anytime or anywhere (c) the maximization of learning opportunities through the use of multiple technologies (d) increased interestingness of the actual course content and (e) course material being more accessible to students with different learning styles or preferences.

Researchers argue that complex learning requires more than the lecture pedagogy to develop problem solving ability in students. In this regard, Shaffer and Small (2004) posit that both collaborative and interactive learning which are integral to blended learning help students to develop problem solving abilities. Owston, York and Murtha (2013) found that high achieving students fared better in a blended learning course than did low achieving students and that overall there were positive correlations between student perceptions of the satisfaction with the course, their engagement, feelings of convenience and learning outcomes and course grades. In a meta-analysis about blended learning and achievement, Vo, Zhu, and Diep (2017) found that blended learning students reported higher achievement levels than those in traditional classes. Also, Sajid, Laheji, Abothenain, Salam, AlJayar, and Obeidat (2016) found that students showed better understanding and retention of course content from blended learning classes. Wilson and Grieg (2017) posit that students were also able to develop practical skills and competencies through online videos provided in blended learning classes.

According to Garrison and Kanuka (2004) there are five steps that increase the efficiency and effectiveness of blended learning models during implementation. These five steps include (three principles) (1) the development of a clear institutional policy direction, (2) increasing the staff awareness of the model to be implemented (3) the establishment of a single point for the requisite support, management and quality assurance of the project (4) the provision of funding to support faculty innovations and initiatives related to transitioning from traditional to blended learning protocols and (5) reliable technology platform and appropriate infrastructure accessible to students, faculty and support 
personnel. Garrison and Kanuka also posit that since restructuring a class from traditional to blended learning is a time consuming process, that there is usually greater incentive to undertake new initiatives when appropriate support mechanisms and incentives are provided.

In general the findings related to attempts at blended learning revealed that an increase attendance when compared with face-to-face classes. In fact, students report that they found the blended learning approach a better way to teach the class. More specifically, almost all students found that factors such as class updates and resources like lectures, webinars and discussion forums were valuable and beneficial. Students also cited the assignments as challenging and suggested their continued use in the future. Some students also felt that the blended learning approach lent itself to an improved understanding of course concepts and an introduction to new technology.

\section{Methodology}

This section will provide information on the participants of the study, the questionnaires used along with the model and procedures that guided the blended learning implementation process.

\section{Participants}

Approximately three hundred students were enrolled in a first year psychology course. From the 300 students 200 participated in the study. All students voluntarily consented to participate in the study. There were 6 (six) lecturers delivering the course in 10 classes across two separate campuses. Five of the six lecturers of the course participated in implementation of the blended learning protocol and gave feedback about the process. These five lecturers also voluntarily consented to participate in the study.

\section{Measures}

Qualitative and quantitative data were collected and analysed from two questionnaires designed for the study as well as YouTube analytics on student views information. The two questionnaires were the Student Blended Learning Experience Questionnaire (SBLEQ) and Teacher Blended Learning Experience Questionnaire (TBLEQ).

The SBLEQ included closed ended questions such as, "Did you find that the online videos added value to the face-to face class?" and "Did you find that the online approach helped you to understand concepts better than face-to face?" The SBLEQ consisted of a total of 9 closed and 4 open ended questions (for e.g. "What did you like about the use of videos from different lecturers? And, " In what ways do you think the blended learning experience can be improved?). Teacher Blended Learning Experience Questionnaire (TBLEQ) consisted of 10 open ended questions. The TBLEQ included questions such as, "What did you like about the blended learning experience this semester?" and "What challenges did you experience with the blended learning experience?" 


\section{Procedure}

The study was designed to capture the implementation of the blended learning protocol and evaluate the blended learning experience. During the process, the curriculum was reorganized and redesigned. Lecture videos were produced to extend the in-class learning experience to online mode. The experiences of students and lecturers were assessed using the two questionnaires and YouTube analytics as articulated above. The actual implementation process is represented in Figure 1, below.

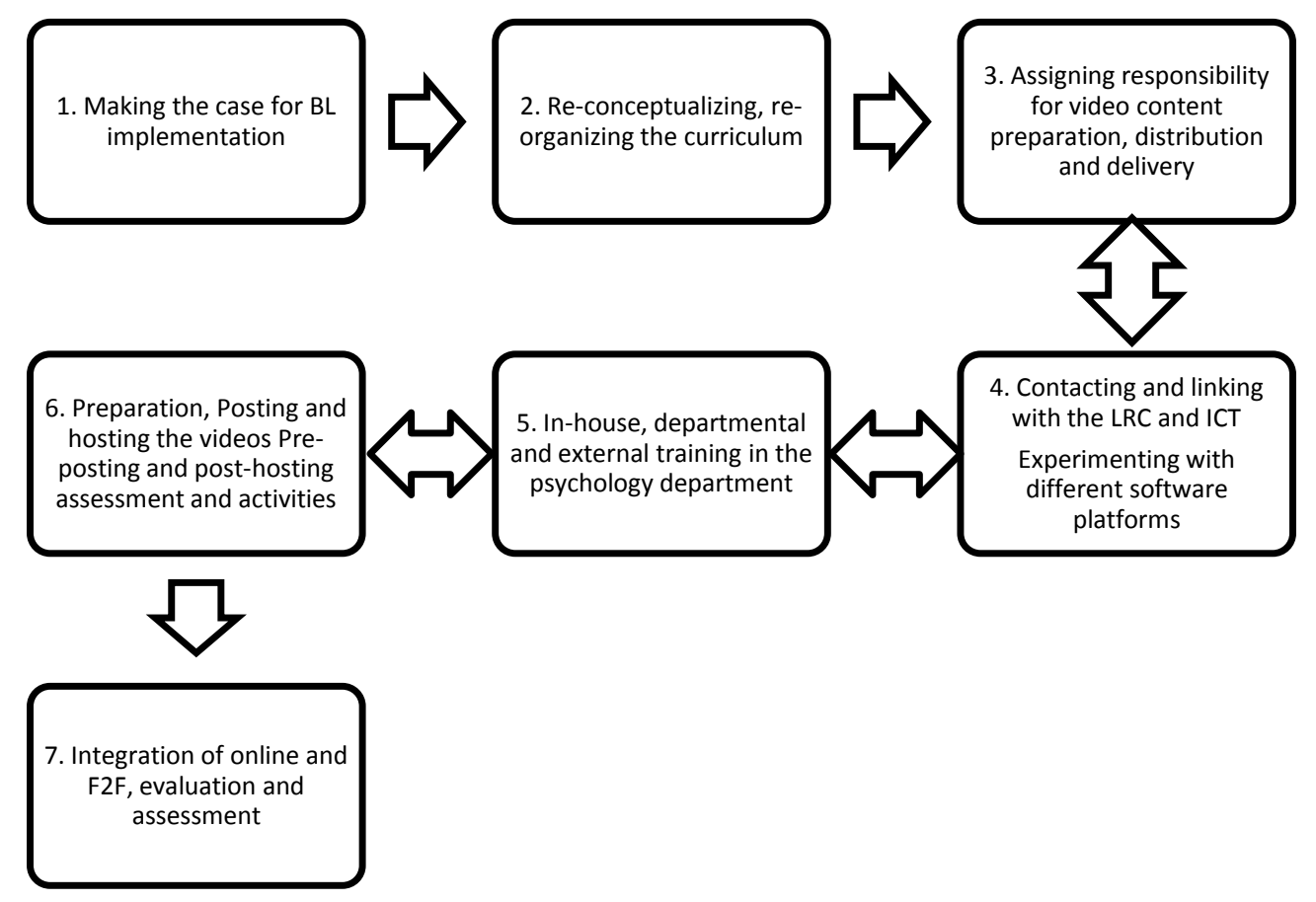

Figure 1. Blended Learning Protocol Implementation Flow Chart

\section{Implementation Protocol}

\section{Making the Case for Blended Learning}

Given the constraints on the scheduling of weekly three-hour face-to-face classes due to staff limitations because of resignations and retirement, the Department where this study was conducted was forced to explore creative alternatives for course delivery. Additionally, there was recognition of the movement away from traditional pedagogic approaches to strategies that facilitated the teaching of students born and socialized in the digital age- digital natives. A third consideration was the need to bring the institution in line with universities worldwide in terms of the delivery of course curricula using integrated platforms that combine face-to-face interaction in the traditional classroom setting with digital technologies. A fourth factor driving the case for implementation of blended learning was the fact that as an institution preparing modern day teachers for ECCE, primary, special education and secondary 
schools we needed to allow prospective teachers to experience this new mode of teaching firsthand as an foundation for their own developing practice. Taking these four main factors into consideration a case was made for trialing a blended approach to teaching a first year psychology course.

The Head of the Department (HOD) also asked for research evidence which was also provided. This evidence revealed that at both secondary and tertiary level studies blending learning was being implemented with great success and benefits to both teachers and students. The HOD therefore agreed for the trial pending the approval of the university Provost. After hearing the arguments presented earlier, the Provost consented. This decision was announced to staff and the response was mixed; some expressed concerns about the 'readiness' of faculty and students, others felt it was long overdue and some were neither for nor against. However, most faculty recognized that blended learning was inevitable as the wave of the present and future, and that preparing prospective teachers using this mode of course delivery would be valuable to them. Faculty also felt that critical training was important in order for the blended approach to work effectively. Thus, it was decided that individual departments would proceed as they felt ready and that training should be accessed both within and outside of the institution. As a result, the scheduling of face-to face class was adjusted to facilitate a two-hour in class engagement and one (1) hour in an online asynchronous mode. The psychology department took up the challenge and this paper is a reflective account of the process and perspectives from those involved.

\section{Re-conceptualizing, re-ogranising the curriculum}

The first order of business was reconceptualising and re-organizing the curriculum. The members of the psychology department sat as a group and decided upon the requisite changes to the curriculum as suggested in the research (Lee, Lim \& Kim, 2017). The main objective was to cover more complex concepts in the traditional classroom and deal with less challenging content online. There was also a need to determine how much content would be delivered in the online mode to engage student meaningfully for an hour. After these decisions were made, the mode of delivery was decided upon. Given the limited experience with blended learning, the department decided to employ the narrated slideshow (Ashley, 2003) with embedded questions to facilitate focus, assessment and evaluation as well as post-lesson dialogue in the regular classroom.

\section{Video content preparation and distribution}

Depending on their individual strengths and preferences, department members chose the parts of the curriculum they wanted to deliver over the 13 teaching weeks of the semester. It was also agreed that the psychology department coordinator would check and vet the online content for quality before distribution to the entire department (six members) and students (there were approximately 300 in 10 classes spread across two separate campus locations). Each psychology department member was responsible for the creation of at least 4 narrated videos for the particular course. The department coordinator took the lead in preparation of the first six videos covering weeks 1-3. 


\section{Experimenting with different platforms}

The next stage was the actual preparation of the videos for the online content. The department coordinator experimented with various video making software before settling on a particular strategy. The tools experimented with were Cyberlink YouCam 6, Wondershare video editor, Mediasite desktop editor and Microsoft PowerPoint voice-over narration. Cyberlink YouCam 6 which was purchased online and downloaded allowed for the preparation of videos that captured both the PowerPoint presentations as well as the lecturer simultaneously. There were also options for full PowerPoint and audio narration without the lecturer being visible and vice versa. The versatility of this video creating tool was fully exploited however, the byte size of a 12-15 minute video proved prohibitive. In fact, after multiple videos were complete it became very challenging to distribute the videos via email to the other lecturers in the department or to upload them to YouTube. The staff members at the university's ICT and university Learning Resource Center (LRC) were engaged but they were unable to reduce the videos to manageable sizes. Wondershare video editor was also utilised for this purpose but this too proved impractical.

\section{Contacting and linking with the LRC and ICT}

Subsequently, the LRC staff advised that the university was engaging with a new lecture recording platform called Mymediasite - an integrated platform for the hosting of online lectures and videos. While this platform is an excellent one for the purpose of blended learning, the required training and technological challenges meant that another approach was needed because the start of the semester was imminent. Eventually, Microsoft PowerPoint was used with voiceover narration explaining the content. These videos were distributed to all department members who then made them available to their classes. Additionally, some videos were also prepared with a free version of ScreencastO-Matic a software application that allows for the integration of applications like PowerPoint and voice narration with some text and other animations. Both applications worked well, was easy to use and were therefore, employed throughout the semester. The completed videos were either uploaded to YouTube and the links communicated to students via Blackboard or they were distributed as files then uploaded to the Blackboard course management system as course content.

\section{In-house and External training for lecturers}

There was one major in-house departmental training session during the semester where the different approaches were demonstrated to lecturers by the department coordinator. After the different demonstrations, members got opportunities to actually use the tools to prepare a short video in the training session. All members who were present successfully completed the exercise but were further directed to other online training tools. The videos produced for this first semester covered the content that had been designated for online mode and delivered to students. 


\section{Gauging student feedback during the semester}

During face-to-face classes formative assessment procedures were used to gauge students' responses to the online content. Students were required to answer questions, engage in post-viewing discussions, and create annotated diagrams and other summaries or engage in critical thinking activities in response to the online content. Lecturers were therefore able to gauge the extent to which students engaged with the online material. Data analytics were also captured for some videos that were posted to YouTube. These analytics allowed lecturers to know the extent to which the video were being accessed given the number of students in each class. After these procedures and processes data were collected using the questionnaires described above. These data were analysed and the results are outlined in the sections below.

\section{Results and Discussion}

Preliminary analyses of the data collected from students revealed that approximately $81 \%$ of them said they preferred the blended learning to the traditional face-to-face (F2F) approach previously employed to deliver their first psychology course during the previous semester.

Eighty-eight percent of students found that the blended learning approach added value to the course while $65 \%$ found that they learnt concepts better in the blended learning environment compared to the F2F teaching protocol. This is similar to the findings of Sajid et al. (2016). Ninety percent of students used the online videos for reiteration of course content and review. However, less than $40 \%$ of students held post-viewing discussions with lecturers on what they did not understand.

When asked why they thought the blended learning approach was better; most students provided at least three answers that included but were not limited to the statements under the various categories in the Table 1 below. From these responses it can be gleaned that students really enjoyed the online classes and benefitted from having more personal time at their disposal, greater autonomy for their learning and a more enriched learning experience. This might account for the higher achievement in STEM blended learning courses than traditional classes previously reported (Vo, Zhu, \& Diep, 2017). 
Table 1. Responses to question: "What made the Blended approach better than Traditional teaching?"

\begin{tabular}{|c|c|c|c|}
\hline $\begin{array}{l}\text { Operationalisation } \\
\text { of Videos }\end{array}$ & Interaction with Content & $\begin{array}{l}\text { Delivery of } \\
\text { Content }\end{array}$ & $\begin{array}{l}\text { Course related } \\
\text { protocols }\end{array}$ \\
\hline $\begin{array}{l}\text { The online video } \\
\text { gives individual } \\
\text { attention }\end{array}$ & $\begin{array}{l}\text { You can view and review the } \\
\text { video at any time }\end{array}$ & $\begin{array}{l}\text { It was more } \\
\text { interesting }\end{array}$ & $\begin{array}{l}\text { School hours are } \\
\text { minimize }\end{array}$ \\
\hline $\begin{array}{l}\text { Videos [were] more } \\
\text { direct }\end{array}$ & $\begin{array}{l}\text { You can pause the video and } \\
\text { research something you don't } \\
\text { understand and start back the } \\
\text { video }\end{array}$ & $\begin{array}{l}\text { More or better } \\
\text { concentration due } \\
\text { to less time }\end{array}$ & $\begin{array}{l}\text { Time to understand } \\
\text { concepts \& ask } \\
\text { questions for guidance } \\
\text { at next class }\end{array}$ \\
\hline \multirow[t]{3}{*}{$\begin{array}{l}\text { It gave me a feel of } \\
\text { what online classes } \\
\text { are like }\end{array}$} & $\begin{array}{l}\text { Students can be comfortable } \\
\text { doing the one hour video at home }\end{array}$ & $\begin{array}{l}\text { Be able to revise } \\
\text { work in simpler } \\
\text { terms than the } \\
\text { textbook }\end{array}$ & \\
\hline & $\begin{array}{l}\text { It gives persons a greater sense of } \\
\text { responsibility for their learning }\end{array}$ & & \\
\hline & $\begin{array}{l}\text { Questions at the end allowed } \\
\text { reflection, Helps to develop a } \\
\text { routine for studying }\end{array}$ & & \\
\hline
\end{tabular}

Concerning the quality of videos, no student rated the videos as "poor," while both average and very good ratings were approximately $50 \%$ each. Eighty percent of students felt that the new blended learning approach allowed them more personal free time and $91 \%$ of students thought that the questions embedded in each video for review and reflection of the content helped them to focus on the key concepts in each video. Students were also asked to list at least three things that made the videos interesting and valuable. Students' responses to this question included but were not limited to the statements captured in the various categories in the Table 2 below. The responses to this question revealed that students were intrigued by the strategies that lecturers used to keep them focused on the concepts to be learnt, the variety of approaches, the succinctness of the content as well as the self-regulated learning that it facilitated. This finding may be the reason why students in the Wilson and Grieg (2017) were able to develop certain practical skills from their blended learning videos. 
Table 2. Responses to the question, "What made the videos interesting and valuable?"

\begin{tabular}{|c|c|c|}
\hline Operationalization of Videos & Interaction with Content & Delivery of content \\
\hline The questions at the end & I can review it over and over & One or two jokes were made \\
\hline $\begin{array}{l}\text { The explanations that was given } \\
\text { on the video and the pictures }\end{array}$ & $\begin{array}{l}\text { The ability to download the video } \\
\text { for later use }\end{array}$ & $\begin{array}{l}\text { Giving examples and } \\
\text { illustrations }\end{array}$ \\
\hline The shortness of the time lol & $\begin{array}{l}\text { I was able to make my notes and } \\
\text { view on my time }\end{array}$ & $\begin{array}{l}\text { Hearing from a number of } \\
\text { different lecturers }\end{array}$ \\
\hline $\begin{array}{l}\text { The amount of info that was } \\
\text { given yet it was straight to the } \\
\text { point }\end{array}$ & $\begin{array}{l}\text { They were interactive, I felt I was } \\
\text { in an individual classroom }\end{array}$ & $\begin{array}{l}\text { Summarized versions not } \\
\text { too lengthy }\end{array}$ \\
\hline $\begin{array}{l}\text { Audio with reinforced visuals, } \\
\text { Cartoons, Other Graphical } \\
\text { effects }\end{array}$ & & \\
\hline
\end{tabular}

Seventy-six percent of students believed that the exposure to videos created by lectures other than their own was a good idea.

Students were also asked to identify an advantage and a disadvantage to exposure to videos created by different lecturers apart from their own. Student's responses included the following as categorized in Table 3 below.

Table 3. Advantages and Disadvantages of Different Lecturers Presenting Videos

\begin{tabular}{|c|c|}
\hline $\begin{array}{c}\text { Advantages of Multiple lecturers' } \\
\text { videos }\end{array}$ & Disadvantages of Multiple lecturers' videos \\
\hline Different teaching styles & Some lecturers were difficult to understand \\
\hline $\begin{array}{l}\text { Because it allowed you a well- } \\
\text { rounded effect in the school }\end{array}$ & Because it confused me the different voices \\
\hline $\begin{array}{l}\text { To familiarize with different } \\
\text { lecturers }\end{array}$ & $\begin{array}{l}\text { Teaching styles were different which made it a } \\
\text { bit difficult to adjust to }\end{array}$ \\
\hline $\begin{array}{l}\text { In meeting we hear other aspects of } \\
\text { the lesson in (a) different ways }\end{array}$ & They were too boring \\
\hline Enjoyed variety & Could not keep up \\
\hline A different voice and focus & Because I prefer my teachers teaching method \\
\hline Different perspectives of the lecturers & $\begin{array}{l}\text { Other lecturers lack enthusiasm and } \\
\text { creativity }\end{array}$ \\
\hline
\end{tabular}




\section{Student Recommendations}

Students were also asked how they felt the online videos could be improved. Student responses to that question are captured in Table 4 below. From the data it can be seen that students felt that there could be an improvement of the quality and content of the material as well as the delivery by faculty. It is interesting to note that some students felt that the interest and richness of the video content need to be translated into the actual face-to-face protocols in some cases. This may have been suggested because lecturers made an extra effort to create interesting videos while maintaining the status quo delivery in the traditional classroom. Students also felt that most post-viewing dialogue and discussion were critical to improving the overall experience. This will probably assist with the clarification of concepts or ideas not fully grasp during the online session.

Table 4. Responses to, "How can the Blended Learning Experience be Improved?"

\begin{tabular}{llll}
\hline $\begin{array}{l}\text { Operationalisation of } \\
\text { Videos }\end{array}$ & $\begin{array}{l}\text { Delivery of } \\
\text { Content }\end{array}$ & $\begin{array}{l}\text { Video Related Support- } \\
\text { framework }\end{array}$ & $\begin{array}{l}\text { Course related } \\
\text { protocols }\end{array}$ \\
\hline Reduce work load & Less robotic talking & $\begin{array}{l}\text { More interactive, Online } \\
\text { feedback if you do not } \\
\text { understand }\end{array}$ & $\begin{array}{l}\text { The face to face } \\
\text { should be more } \\
\text { like the videos }\end{array}$ \\
Make videos shorter & $\begin{array}{l}\text { Videos to be on } \\
\text { time }\end{array}$ & $\begin{array}{l}\text { Group discussions on } \\
\text { different topics, Open } \\
\text { forum for discussion } \\
\text { A website to better } \\
\text { access them }\end{array}$ & $\begin{array}{l}\text { In-class recap of } \\
\text { video }\end{array}$ \\
$\begin{array}{l}\text { Add animations to } \\
\text { keep learner's interest }\end{array}$ & & $\begin{array}{l}\text { MCQs with answer } \\
\text { sheet so students can test } \\
\text { their understanding }\end{array}$ & \\
$\begin{array}{l}\text { Better audio, Longer } \\
\text { pauses between slides }\end{array}$ & & & \\
$\begin{array}{l}\text { Live videos, Longer } \\
\text { videos and more } \\
\text { online time }\end{array}$ & & & \\
\hline
\end{tabular}

\section{Analysis of Responses from Teachers Blended Learning Experience Questionnaire (TBLEQ)}

In terms of positive experiences about making the transition from traditional to blended learning, lecturers reported having more time at their disposal to engage in teaching innovations, in-depth examination of course concepts and opportunities to broaden their pedagogical base and give students control and independence. Concerning time usage some lecturers" said, "It allowed more time for innovation and creativity" and "I enjoyed having the freedom to explore different aspects of the topic that were previously challenging due to time constraints."

Some lecturers enjoyed giving students more autonomy, supporting statements include, [it] "Created an opportunity to allow students some control and 
independence and the opportunity for students to be more self-regulated. The shorter face-to-face class was beneficial because usually after about 2 hours students would sometimes become restless." Others were happy because they felt the blended learning experience "allowed more time for innovation and creativity," to "try something different" and the "opportunity for me to learn new skills. It was quite a learning experience for me."

In terms of challenges that lecturers experienced, most identified issues related to the creation, hosting and accessing of videos produced for the course. Quotes related to the challenges they experienced included, "creating the videos and having a platform to host them," "getting appropriate software that was easy to use to create the videos," "getting the videos done was very time-consuming," and "the main challenge was that some students did not access the online presentations, apparently they were waiting for the usual exam cram-sessions." And "trying to condense the content - you can't put down everything you would say if you were face-to-face. Trying to make it interactive."

When asked which approach they preferred, all lecturers signaled a preference for the blended approach. They offered responses such as: "No, the new format is more versatile and flexible," "I prefer the new 2 hour in-class arrangement," and "especially from a brain-based perspective, I prefer the 2-hour sessions. It is also a great opportunity to include technology in our teaching."

Lecturers were also asked to identify ways in which they felt the blended approach affected students' attitudes and behaviours. Some reported that students appear to enjoy the class more because they "seem more relaxed and engaging in class," "some students looked forward to viewing them every week." "Some latecomers began to arrive a bit earlier." On the contrary, one lecturer said, "Sometimes I wondered if they were all viewing the videos. I did not notice any change of attitude really. Sometimes when I referred to something from a past video, some of them did not have a clue."

Regarding exposing their students to videos and material prepared by other lecturers, most lecturers valued the opportunity. They said things such as, "it was very interesting to see the strategies and the creativity of my colleagues in the department," "I was quite happy to expose my students to others," "I feel a sense of pride, knowing that we don't have to depend on "foreign" sources for all information" and "I welcomed it! It sometimes gave a different perspective which we could learn from and use in other classes."

Lecturers were also asked for ideas to improve the blended learning experience for students. In this regard, they proffered the following: "Better streamlined and structured videos with lecturers visible with built-in assessment," "Live classes with immediate feedback," "Online discussion and collaboration asynchronously," "The students need to become self-regulated learners, they are still in dependency mode," and "Make it more interactive by including other types of technology - blogs, discussion boards etc. (I will have to learn more about these too!). Some means of ensuring that they do interact with the material." In terms of improving the blended learning experience for lecturers, they said, "More training and collaboration," "Exposure and use of more Web 2.0 tools," "I believe that we all benefitted from the experience and we can only 
go from strength to strength," and "training sessions (at both campuses not just one campus). We should try other types next semester if we are continuing the blended learning approach."

Lecturers were also asked to sum up their first attempt at blended learning and they stated the following, "It was a great first experience from thought to actual expression and articulation. Wow!" "It was very rewarding," and "It was quite a learning experience for me. I actually enjoyed it. However, it took me a lot of time since I was acquiring the skills as I went along. What with all the other demands at the university at that time, time was a problem. All in all, I am happy we did it."

\section{Limitations of the study}

This study had a few limitations. First was the fact that the data was gathered over one semester and upon first implementation of the blended learning approach so teething problems could be expected. Probably a longer time frame could be considered for future research in this area. Additionally, the online lectures were basically done in asynchronous mode which to an extent limits certain comparisons with face-to-face teaching protocols. However, the latter can be a consideration for future research where synchronous, asynchronous and traditional learning might be compared and contrasted.

\section{Conclusion}

Overall, the blended learning experience was very fruitful and developmental. We opted for a soft approach using the asynchronous mode which lays a solid platform for going further in the development of pedagogic approaches using contemporary digital technologies. As the institution has migrated for Blackboard to canvas which allow for Zoom lecture integration, Mymediasite and other modes that facilitate blended learning protocols the stage is set for future growth in teaching and preparing millennials for the teaching in a vastly changing digital world. This research offers additional value because it not only captures lecturers' perspectives but students' own as well. In this regard, it offers considerable information in terms of what students and teachers enjoy about the blended learning experience in asynchronous mode as well as critical factors to be considered in making the switch form face-to-face only pedagogy and improving on it.

\section{Recommendations}

Some possible directions for the improvement of the blended learning experience may include improving the criteria for assessing the students' contributions, improving the students' homework submission procedures and providing them with more opportunities for collaboration for critical considerations. Creating and using available learning management systems for post-lesson dialogue and reflection with and among students. This new way of building a teaching system based upon skill development while meeting the given learning goals is making teachers rethink the pedagogical paradigm, as the whole process is student-oriented and assumes the existence of a dynamic curriculum (Arani, 2015). 


\section{References}

Arani, J. A. (2015). A Blended-Learning Setting in English for Medical Purposes Course Incorporating Competencies. International Journal of Advanced Corporate Learning, 8(1), 12-15. doi:10.3991/ijac.v8i1.4350.

Ashley, J. (2003, December). Synchronous and Asynchronous Communication Tools. Executive Online Update. Retrieved from http://www.asaecenter.org/Resources/articledetail.cfm?itemnumber=13572.

Boelens, R., Voet, M., \& De Wever, B. (2018). The design of blended learning in response to student diversity in higher education: Instructors' views and use of differentiated instruction in blended learning. Computers \& Education, 120, 197212. doi:10.1016/j.compedu.2018.02.009.

Garrison, R.D. \& Kanuka, H. (2004) “Blended Learning: Uncovering its transformative potential in higher education," Internet and Higher Education, 7(2), pp. 95-105.

Heinze, A. (2008) Blended learning: An interpretive action research study, (Unpublished Ph.D. thesis) University of Salford.

Lee, J., Lim, C., \& Kim, H. (2017). Development of an instructional design model for flipped learning in higher education. Educational Technology Research $\mathcal{E}$ Development, 65(2), 427-453. doi:10.1007/s11423-016-9502-1.

Luke, J. K., \& Morrissey, J. L. (2014). Integrating Online Pedagogy into Kinesiology: Service Learning for Kinesiology Majors. Kinesiology Review, 3(4), 258-262.

Munir, A. R., \& Prem, K. D. (2014). Implementing blended learning into the academic programs of Rajiv Gandhi University of Health Sciences, Karnataka. Journal Of Complementary \& Integrative Medicine, 11(2), 147-150.

Owston, R., York, D., \& Murtha, S.(2013). Student Perceptions and Achievement in a University Blended Learning Initiative. Internet and Higher Education, vol. 28, 3846.

Park, Y., Yu, J. H., \& Jo, I. (2016). Clustering blended learning courses by online behavior data: A case study in a Korean higher education institute. Internet $\mathcal{E}$ Higher Education, 291-11. doi:10.1016/j.iheduc.2015.11.001.

Porter, W. W., \& Graham, C. R. (2016). Institutional drivers and barriers to faculty adoption of blended learning in higher education. British Journal Of Educational Technology, 47(4), 748-762. doi:10.1111/bjet.12269.

Sajid, M. R., Laheji, A. F., Abothenain, F., Salam, Y., AlJayar, D., \& Obeidat, A. (2016). Can blended learning and the flipped classroom improve student learning and satisfaction in Saudi Arabia?. International Journal Of Medical Education, 7281-285. doi:10.5116/ijme.57a7.83d4.

Shaffer, K., Small, J.E. (2004). Blended learning in medical education: use of an integrated approach with web-based small group modules and didactic instruction for teaching radiologic anatomy. Acad Radiol; 11(2), 147-150.

Tshabalala, M., Ndeya-Ndereya, C., \& van der Merwe, T. (2014). Implementing Blended Learning at a Developing University: Obstacles in the Way. Electronic Journal of E-Learning, 12(1), 101-110.

Vo, H. M., Zhu, C., \& Diep, N. A. (2017). The effect of blended learning on student performance at course-level in higher education: A meta-analysis. Studies In Educational Evaluation, 5317-28. doi:10.1016/j.stueduc.2017.01.002.

Wilson, L. M., \& Greig, M. (2017). Students' experience of the use of an online learning channel in teaching and learning: A sports therapy perspective. International Journal Of Therapy \& Rehabilitation, 24(7), 289-296. doi:10.12968/ijtr.2017.24.7.289. 